\title{
Pulmonary $\mathrm{NO}$ synthase inhibition and inspired $\mathrm{CO}_{2}$ : effects on $V^{\prime} / Q^{\prime}$ and pulmonary blood flow distribution
}

\author{
T.V. Brogan*, R.G. Hedges**, S. McKinney**, H.T. Robertson**, \\ M.P. Hlastala**, E.R. Swenson***
}

Pulmonary $\mathrm{NO}$ synthase inhibition and inspired $\mathrm{CO}_{2}$ : effects on $\mathrm{V}^{\prime} / \mathrm{Q}^{\prime}$ and pulmonary blood flow distribution. T.V. Brogan, R.G. Hedges, S. McKinney, H.T. Robertson, M.P. Hlastala, E.R. Swenson. C ERS Journals Ltd 2000.

ABSTRACT: Inhaled carbon dioxide decreases ventilation/perfusion ratio $\left(V^{\prime} / Q^{\prime}\right)$ heterogeneity in dogs. The aim of this study was to test whether inhaled $\mathrm{CO}_{2}$ improves the $V^{\prime} / Q^{\prime}$ by inhibition of nitric oxide production and whether inhibition of endogenous NO production in the lung alters gas exchange and $V^{\prime} / Q^{\prime}$ matching.

Eleven healthy dogs were anaesthetized and mechanically ventilated. The multiple inert gas elimination technique (MIGET) was used to measure $V^{\prime} / Q^{\prime}$ heterogeneity and regional pulmonary blood flow heterogeneity was assessed in five dogs using fluorescent microspheres. In a separate set of five dogs, exhaled NO levels were measured via chemiluminescence. All dogs were studied before and after $4.8 \%$ inspired $\mathrm{CO}_{2}$, and then given the NO synthase inhibitor $N^{\omega}$-nitro-L-arginine methyl ester (LNAME, $\left.10 \mathrm{mg} \cdot \mathrm{kg}^{-1}\right)$ via nebulization, after which they were studied again with room air and inhaled $\mathrm{CO}_{2}$.

$\mathrm{CO}_{2}$ and L-NAME improved arterial and alveolar oxygen tension, but the improvements with L-NAME did not reach statistical significance. Improved $V^{\prime} / Q^{\prime}$ matching, as assessed by the MIGET, occurred under all experimental conditions. Exhaled NO levels were reduced by $40 \%$ with $\mathrm{CO}_{2}$ and $70 \%$ with L-NAME. The standard deviation of regional pulmonary blood flow assessed via microspheres decreased only with inhaled $\mathrm{CO}_{2}$. Fractal analysis of pulmonary blood flow distributions revealed that regional blood flow was highly correlated with flow to neighbouring pieces of lung in all four conditions with no changes in the fractal dimension.

Inspired carbon dioxide improves ventilation perfusion ratio matching and is associated with a more homogeneous distribution of pulmonary blood flow. Although inspired carbon dioxide causes a reduction in exhaled nitric oxide, the differences in pulmonary perfusion distributions found between carbon dioxide and $N^{\omega}$-nitro-Larginine methyl ester suggest that the carbon dioxide effect is not mediated by a reduction in nitric oxide production. The improved ventilation perfusion ratio matching with inhibition of nitric oxide synthase suggests the intriguing possibility requiring further study that endogenous production of nitric oxide in the lung does not subserve ventilation perfusion ratio regulation.

Eur Respir J 2000; 16: 288-295.

*Dept of Paediatrics, Children's Hospital and Medical Centre, **Depts of Physiology and Biophysics and of Medicine and $* * *$ Medical Service, Puget Sound Veterans Affairs Medical Centre, University of Washington, Seattle, WA, USA.

Correspondence: T.V. Brogan

Dept of Paediatrics

Children's Hospital and Regional Medical Centre

4800 Sand Point Way NE, CH-05

Seattle, WA 98105-0371

USA

Fax: 12065273935

Keywords: Hypercapnia

hypoxic pulmonary vasoconstriction

nitric oxide

nitric oxide synthase

pulmonary blood flow

ventilation/perfusion matching

Received: September 81999

Accepted after revision April 252000

This work was supported by National Institutes of Health grant HL45771 to E.R. Swenson and HL12174 to M.P. Hlastala.

Addition of low concentrations (2-5\%) of carbon dioxide to inspired gas improves gas exchange and arterial oxygenation in normal lungs $[1,2]$. Using the multiple inert gas elimination technique (MIGET), it was demonstrated that inspired $\mathrm{CO}_{2}$ reduces ventilation/perfusion ratio $\left(V^{\prime} / Q^{\prime}\right)$ heterogeneity even with constant ventilation [3]. Although $\mathrm{CO}_{2}$ has many effects on the lungs that may promote $V^{\prime} / Q^{\prime}$ matching $[4,5]$, it remains unknown how and at what site(s) $\mathrm{CO}_{2}$ decreases $V^{\prime} / Q^{\prime}$ heterogeneity.

Changes in $\mathrm{CO}_{2}$ concentration or the accompanying $\mathrm{pH}$ may affect airways, parenchyma or vessels directly or indirectly through modulation of effector substances such as prostaglandins [6] or calcium [7]. Of considerable interest, also, is nitric oxide, which is vaso- and bronchodilating $[8,9]$ as well as a neurotransmitter in nonadrenergic noncholinergic nerves [10]. Thus changes in local NO production may alter vascular and bronchial tone to regulate the local $V^{\prime} / Q^{\prime}$. NO synthase (NOS), which catalyses the conversion of L-arginine to $\mathrm{NO}$ and L-citrulline, is sensitive to changes in $\mathrm{pH}$, and in general is inhibited by acidosis [11-16]. In the guinea-pig, $6 \% \mathrm{CO}_{2}$ causes a reduction in exhaled NO of $60 \%$ [17] and, in the rabbit, of $30 \%$ [18]. In the isolated perfused rabbit lung, low concentrations of $\mathrm{CO}_{2}$ cause a decrease in levels of exhaled NO [19] and NO metabolites measured in the perfusate [20].

These experiments show that alterations in $\mathrm{CO}_{2}$ concentration affect $\mathrm{NO}$ production in the lung, suggesting that inspired $\mathrm{CO}_{2}$ might elicit its effects on $V^{\prime} / Q^{\prime}$ heterogeneity through changes in NO metabolism in the airways, nerves or vessels. It was hypothesized that inhibition of lung NOS should mimic the effect of inhaled $\mathrm{CO}_{2}$ on $V^{\prime} / Q^{\prime}$ relationships in the lung and not further reduce $V^{\prime} /$ $Q^{\prime}$ heterogeneity when combined with $\mathrm{CO}_{2}$. In order to 
test whether the mechanism of action of inspired $\mathrm{CO}_{2}$ on $V^{\prime} / Q^{\prime}$ matching results from altering $\mathrm{NO}$ production and to examine whether endogenous NO formation, itself, affects $V^{\prime} / Q^{\prime}$ heterogeneity and pulmonary blood flow distribution, nebulized $N^{\omega}$-nitro-L-arginine methyl ester (LNAME), a nonspecific inhibitor of NOS, was administered. This method of L-NAME administration was chosen to limit NOS blockade to the lung and minimize systemic NOS inhibition. $V^{\prime} / Q^{\prime}$ relationships were examined via the MIGET and regional pulmonary blood flow was assessed using fluorescent microspheres. Effects on lung NO production were measured via changes in exhaled NO levels analysed by chemiluminescence.

\section{Methods}

\section{Animal instrumentation and support}

Studies were performed on healthy mixed-breed dogs (weight range, $20-28 \mathrm{~kg}$ ) in the supine position under barbiturate anaesthesia $\left(20-30 \mathrm{mg} \cdot \mathrm{kg}^{-1}\right.$ i.v. sodium pentothal induction with supplemental doses, $1-2 \mathrm{mg} \cdot \mathrm{kg}^{-1}$ as needed every 30-60 min). The animals were intubated with a cuffed endotracheal tube. Femoral arterial and venous catheters and a jugular 7-F thermodilution catheter were inserted. Temperatures were monitored with a rectal thermometer. Ventilation was administered by means of a piston pump ventilator at a tidal volume of $12-13 \mathrm{~mL} \cdot \mathrm{kg}^{-1}$ and a frequency of $14-16$ breaths $\cdot \mathrm{min}^{-1}$. The ventilator was supplied with gas from tanks that were free of NO $(<0.5$ parts per billion (ppb)). Every $5 \mathrm{~min}$, a single $30-\mathrm{mL} \cdot \mathrm{kg}^{-1}$ breath was provided to prevent atelectasis. Once an acceptable rate of ventilation was determined via arterial blood gas analysis (arterial pH, 7.39-7.45; arterial carbon dioxide tension $\left.\left(\mathrm{Pa}, \mathrm{CO}_{2}\right), 4.3-4.7 \mathrm{kPa}(32-35 \mathrm{mmHg})\right)$, no further changes were made to the ventilator settings. Following the experiment, the dogs were sacrificed by means of an overdose of sodium thiopental. All aspects of procurement, care, nutrition, anaesthetic use and euthanasia in these experiments followed the guidelines of the American Physiological Society (published regularly in the Journal of Applied Psychology) for the protection of vertebrate animals used for experimental and other scientific purposes.

\section{Haemodynamics and respiratory gas exchange measure- ments}

Pulmonary and systemic arterial pressures, airway pressures, and mixed expired carbon dioxide $\left(\mathrm{PCO}_{2}\right)$ and oxygen tension $\left(\mathrm{PO}_{2}\right)$ were continuously recorded on an eight-channel recorder (Hewlett-Packard, Palo Alto, CA, USA). At specified intervals, pulmonary artery occlusion pressure, thermodilution cardiac outputs and mixed expired $\mathrm{PO}_{2}$ and $\mathrm{PCO}_{2}$ (sampled from a 3-L mixing box) were determined. The $\mathrm{PO}_{2}$ and $\mathrm{PCO}_{2}$ in expired gas were measured using a mass spectrometer (Perkin-Elmer Medical Gas Analyzer MGA-1100; Perkin-Elmer Norwalk, CT, USA). Blood $\mathrm{pH}$ and oxygen and carbon dioxide tension were measured in arterial $\left(P \mathrm{a}, \mathrm{O}_{2}\right.$ and $\left.P \mathrm{a}, \mathrm{CO}_{2}\right)$ and mixed venous $\left(P_{\mathrm{v}}, \mathrm{O}_{2}\right.$ and $\left.P_{\mathrm{v}}, \mathrm{CO}_{2}\right)$ blood using a blood gas analyser (Radiometer BMS-3; Radiometer America, Westlake, $\mathrm{OH}, \mathrm{USA}$ ) maintained at $37^{\circ} \mathrm{C}$ and corrected to the measured temperature. Oxygen consumption $\left(V^{\prime} \mathrm{O}_{2}\right)$ and carbon dioxide production $\left(V^{\prime} \mathrm{CO}_{2}\right)$ were calculated by analysis of expired gases using appropriate temperature, pressure and water content corrections.

Respiratory gas exchange was assessed by analysis of arterial and mixed venous blood gas levels. In calculating the alveolar/arterial tension difference for oxygen, $\left(\mathrm{PA}-\mathrm{a}, \mathrm{O}_{2}\right)$, the complete alveolar gas equation incorporating inspiratory carbon dioxide fraction $\left(F \mathrm{I}, \mathrm{CO}_{2}\right)[3]$ was used:

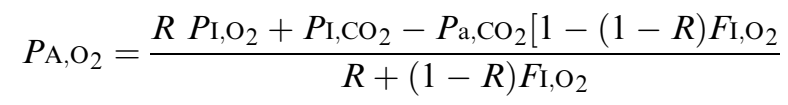

where $R$ is the respiratory gas exchange ratio $\left(V^{\prime} \mathrm{CO}_{2} /\right.$ $\left.V^{\prime} \mathrm{O}_{2}\right), P \mathrm{I}, \mathrm{O}_{2}$ and $P \mathrm{I}, \mathrm{CO}_{2}$ are the inspiratory oxygen and carbon dioxide tension, $F \mathrm{I}, \mathrm{O}_{2}$ is the inspiratory oxygen fraction, and $P \mathrm{~A}, \mathrm{O}_{2}$ is the alveolar oxygen tension. $\mathrm{Pa}, \mathrm{CO}_{2}$ was assumed to be the same as alveolar carbon dioxide tension.

\section{Inert gas exchange measurements}

$V^{\prime} / Q^{\prime}$ relationships were determined by means of the MIGET [21, 22] using constant infusion of a dilute solution of six inert gases (sulphur hexafluoride, ethane, cyclopropane, halothane, diethyl ether and acetone) dissolved in $5 \%$ dextrose as described by WAGNER and coworkers $[21,22]$. The gas extraction method of WAGNER et al. [21] was used to determine inert gas tensions and solubilities in blood samples. Inert gas indices were calculated from the 50-compartment model of WAGNER et al. [21]. $V^{\prime} / Q^{\prime}$ heterogeneity was also assessed by the arterial/alveolar inert gas difference area $((\mathrm{a}-\mathrm{A}) \mathrm{D}$ area; an integrated value of the subtraction of areas bounded by the alveolar and arterial tensions of the six inert gases when plotted against blood gas solubility on a log scale) derived directly from the retention and excretion data [23]. All inert gas data are the mean of duplicate measurements.

\section{Experimental protocols}

Each dog underwent the same protocol, serving as its own control. After stabilization and a 20-min period of ventilation with room air, baseline haemodynamic (cardiac output, cardiac frequency, and systemic and pulmonary artery pressures), ventilation and respiratory gas exchange (arterial and mixed venous blood gas levels, minute ventilation, airway pressures, and $V^{\prime} \mathrm{O}_{2}$ and $V^{\prime} \mathrm{CO}_{2}$ ), and inert gas exchange measurements were taken. Following these measurements, the animal was ventilated with $4.8 \% \mathrm{CO}_{2}$ (as measured in the inspiratory gas by mass spectrometry) and $20.9 \% \mathrm{O}_{2}$. After $20 \mathrm{~min}$, all measurements were repeated and the animal was then returned to room air ventilation. Next, $40 \mathrm{mg} \cdot \mathrm{mL}^{-1}$ L-NAME in saline was nebulized using an updraft nebulizer until systemic blood pressure rose by $\leq 10 \%$. This required a mean total nebulized dose of $10-15 \mathrm{mg} \cdot \mathrm{kg}^{-1}$.

L-NAME was administered by nebulization with the aim of generating a slight increase in systemic blood pressure to ensure maximal lung NOS inhibition but to avoid the profound systemic hypertension, cardiac output depression and $P \mathrm{v}, \mathrm{O}_{2}$ reduction that occur when large doses of $\mathrm{L}-$ NAME are given systemically [24]. Hence, it was attempted to minimize the potential extrapulmonary influences of L-NAME on $V^{\prime} / Q^{\prime}$ heterogeneity [25]. Twenty minutes later, all measurements were repeated. Then, while the 
slight systemic hypertensive effect of nebulized L-NAME was still measurable (indicating a sustained level of NOS inhibition), the dog was ventilated with $4.8 \% \mathrm{CO}_{2}$ for 20 min and all measurements repeated. The steps of ventilation with room air and $\mathrm{CO}_{2}$ were alternated in successive dogs.

\section{Microsphere injection}

In the final five dogs, changes in pulmonary blood flow were measured using injectable fluorescent microspheres. Fluorescent $15-\mu \mathrm{m}$-diameter microspheres (FluosSpheres; Molecular Probes, Eugene, OR, USA) of six different colours (red, crimson, scarlet, orange, yellow-green and bluegreen) were injected through an i.v. catheter in a superficial leg vein over $30 \mathrm{~s}$ in $5 \mathrm{~mL}$ normal saline, followed by a 10$\mathrm{mL}$ saline flush. The microspheres were sonicated and agitated on a vortex mixer before injection. During each of the four experimental conditions, at the time that other measurements were taken, one colour of microsphere was injected.

Following completion of the experiment, the animals were deeply anaesthetized, given heparin, exsanguinated and killed by intravenous pentobarbital sodium injection. A sternotomy was performed, large-bore catheters were placed in the pulmonary artery and left atrium and the thoracic aorta was tied off. The lungs were perfused with normal saline and $2 \%$ dextran $(74,000 \mathrm{Da})$ until clear of blood, removed from the chest and allowed to dry inflated at an airway pressure of $25 \mathrm{cmH}_{2} \mathrm{O}$.

When dry, the lungs were coated with Kwik foam (DAP Inc., Dayton, OH, USA), suspended vertically in a plasticlined square box and embedded in rapidly setting urethane foam (908gm polyol and isocyanate; International Sales, Seattle, WA, USA) to create a rigid form to which a threedimensional co-ordinate system could be applied. The foam block was then cut into uniform slices and the sections cored using a $1-\mathrm{cm}$ coring tool. Foam adhering to the lung pieces was removed. Each lung piece was weighed and assigned a three-dimensional co-ordinate and lobe designation.

The fluorescent signals for each colour were determined by extracting the fluorescent dyes from each piece with an organic solvent and then measuring the concentrations of fluorescence in each sample [26]. The dataset for each dog consisted of $\mathrm{x}, \mathrm{y}$, and $\mathrm{z}$ co-ordinates, lobe designation, weight and relative flow for each lung piece. The relative blood flow to each lung piece was divided by the weight of each piece and normalized to the mean, providing a relative weight-normalized flow per piece.

\section{Measurement of exhaled nitric oxide}

In order to evaluate the extent of pulmonary NOS inhibition by inhaled L-NAME and $\mathrm{CO}_{2}$ exhaled NO levels were measured via chemiluminescence (nitric oxide analyzer 2700B; Sievers, Boulder, CO, USA) in a separate set of five dogs ventilated with NO-free gas. The mixed expired gas was continuously sampled for NO from the expiratory mixing box. The analyser was connected to a Strawberry Tree Workbench V3.04 (Strawberry Tree, Inc., Sunnyvale, CA, USA) for continuous recording and calibrated to NO-free gas.

\section{Statistical analysis}

All data are presented as mean \pm SD and were analysed by analysis of variance followed by Scheffe's and Bonferroni/ Dunn post hoc tests corrected for multiple comparisons of similar data sets and for comparisons over time. Differences between individual experimental points were analysed by means of the Wilcoxon signed-rank test. The Pearson correlation coefficient calculated between perfusion to lung pieces within a dog was used to quantify the relationship between regional perfusion under different conditions. The coefficient of variation (CV) was used to characterize perfusion heterogeneity within each dog over space or time.

Additionally, fractal analysis of the microsphere data for all five dogs was performed for all conditions, following the method of GLENNY and ROBERTSON [27]. Briefly, fractal analysis represents an approach to the characterization of organ blood flow heterogeneity independent of scale of tissue sampled. The fractal dimension is calculated from the coefficient of blood flow to individual pieces of lung. Small neighbouring lung pieces are combined into a larger conglomerate piece based on multiples $(2,3,4,6$, $8,12,16,24,32,48$ and 64$)$ of the initial central piecesize. The CV of blood flow is then calculated as if the lung had been divided into the larger conglomerate pieces. Conglomerates are restricted to lie entirely within the right or left lung but may traverse lobes. The algorithm for dividing the lung in this way is repeated for each conglomerate of $\mathrm{n}$ pieces a total of $\sqrt{\mathrm{n}}$ times, obtaining $\sqrt{\mathrm{n}}$ CVs. The mean of the logarithm of the $\sqrt{n}$ CVs is used for regression modelling to obtain the fractal dimension (D). The SD of the logarithm of the $\sqrt{n} \mathrm{CVs}$ is used for plotting error bars. The total number of conglomerate pieces for all $\sqrt{ }$ repetitions is used as the regression weight at piece n. $\log C V$ is plotted against logpiece-size and a regression line obtained using weighted regression analysis. The D is calculated from 1 - slope, where slope is obtained from the regression line fitted to the $\log \mathrm{CV}$ versus logpiecesize data.

A p-value of $<0.05$ was considered statistically significant.

\section{Results}

The haemodynamic, ventilatory and metabolic effects of $4.8 \% \mathrm{CO}_{2}$, L-NAME and $\mathrm{CO}_{2}$ following L-NAME are listed in table 1 . Mean systemic blood pressure increased significantly with L-NAME and with L-NAME plus $\mathrm{CO}_{2}$. Pulmonary artery pressure increased under all three experimental conditions, approaching statistical significance with L-NAME alone $(\mathrm{p}=0.061)$ and achieving significance with L-NAME plus $\mathrm{CO}_{2}$. Pulmonary vascular resistance (PVR) increased significantly after both LNAME conditions. Cardiac output increased significantly with inspired $\mathrm{CO}_{2}$. Inspired $\mathrm{CO}_{2}$ produced a decrease in $V^{\prime} \mathrm{O}_{2}$ that approached significance $(\mathrm{p}=0.063)$. L-NAME caused a significant increase in $V^{\prime} \mathrm{CO}_{2}$ although $V^{\prime} \mathrm{O}_{2}$ was unaffected. Pulmonary capillary occlusion pressure, peak airway pressure, haematocrit and temperature did not change significantly under any of the experimental conditions. Minute ventilation was fixed throughout at $6.4 \pm$ $1.01 \mathrm{~L} \cdot \mathrm{min}^{-1}$ as was the $F \mathrm{I}, \mathrm{O}_{2}$ at 0.209 . 
Table 1. - Haemodynamic, ventilatory and metabolic measurements

\begin{tabular}{|c|c|c|c|c|}
\hline & Baseline & $\mathrm{CO}_{2}$ & L-NAME & $\mathrm{CO} 2+\mathrm{L}-\mathrm{NAME}$ \\
\hline SBP mmHg & $113 \pm 16$ & $114 \pm 20$ & $121 \pm 17 *$ & $124 \pm 17^{*}$ \\
\hline$P$ pa $\mathrm{mmHg}$ & $14.6 \pm 4.1$ & $16.2 \pm 5.7$ & $16.0 \pm 5.9$ & $19.2 \pm 7.4 *$ \\
\hline$O^{\prime} \mathrm{L} \cdot \min ^{-1}$ & $3.9 \pm 0.9$ & $4.5 \pm 1.0 *$ & $3.8 \pm 0.6$ & $3.8 \pm 0.8$ \\
\hline PAOP $\mathrm{mmHg}$ & $6.4 \pm 2.2$ & $6.7 \pm 1.9$ & $6.0 \pm 2.4$ & $6.6 \pm 2.7$ \\
\hline$V^{\prime} \mathrm{O}_{2} \mathrm{~L} \cdot \mathrm{min}^{-\mathrm{P}}$ & $0.155 \pm 0.045$ & $0.142 \pm 0.0247$ & $0.155 \pm 0.058$ & $0.144 \pm 0.056$ \\
\hline$V^{\prime} \mathrm{CO}_{2} \mathrm{~L} \cdot \mathrm{min}^{-1}$ & $0.139 \pm 0.053$ & $0.128 \pm 0.050$ & $0.154 \pm 0.06^{*}$ & $0.147 \pm 0.054$ \\
\hline PVR dyne $\cdot \mathrm{s} \cdot \mathrm{cm}^{-5}$ & $212 \pm 60$ & $218 \pm 56$ & $265 \pm 98^{*}$ & $349 \pm 102 *$ \\
\hline
\end{tabular}

Data are presented as mean \pm SD. L-NAME: $N^{\omega}$-nitro-L-arginine methyl ester; SBP: mean systemic blood pressure; $P$ pa: mean pulmonary artery pressure; $Q^{\prime}$ : cardiac output; PAOP: pulmonary artery occlusion pressure, $V^{\prime} \mathrm{O}_{2}$ : oxygen consumption; $V^{\prime} \mathrm{CO}_{2}$ : carbon dioxide production; PVR: pulmonary vascular resistance. *: $\mathrm{p}<0.05$ versus baseline. $(1 \mathrm{mmHg}=0.133 \mathrm{kPa}$.)

Table 2 gives the respiratory gas exchange measurements for each of the four conditions. Inspired $\mathrm{CO}_{2}$ produced the expected acute respiratory acidosis and improvement in $\mathrm{Pa}, \mathrm{O}_{2}$. L-NAME caused an increase in $\mathrm{Pa}, \mathrm{O}_{2}$ but this did not achieve statistical significance. $P \mathrm{v}, \mathrm{O}_{2}$ increased significantly with inspired $\mathrm{CO}_{2} . P A, \mathrm{O}_{2}$ increased significantly with $\mathrm{CO}_{2}$ and with $\mathrm{CO}_{2}$ plus L-NAME. PA$\mathrm{a}, \mathrm{O}_{2}$ improved under all experimental conditions but not significantly. There were significant decreases in arterial/ mixed expiratory tension difference for carbon dioxide with inspired $\mathrm{CO}_{2}$ and L-NAME plus $\mathrm{CO}_{2}$.

Exhaled NO levels, measured in a separate set of five dogs, were low at baseline $(2.2 \pm 1.8 \mathrm{ppb})$. Inhaled $\mathrm{CO}_{2}$ lowered NO levels by $\sim 40 \%$ to $1.3 \pm 1.2 \mathrm{ppb}(\mathrm{p}<0.05)$. Exhaled NO levels fell $\sim 70 \%$ to $0.7 \pm 1.0 \mathrm{ppb}(\mathrm{p}<0.05)$ with L-NAME. Addition of $\mathrm{CO}_{2}$ produced no further decrease in exhaled NO levels $(0.6 \pm 0.8 \mathrm{ppb})$. All changes in exhaled NO levels reached statistical significance $(\mathrm{p}<0.05$ compared to baseline).

Table 3 shows that the (a-A)D area for the six inert gases, a global measure of $V^{\prime} / Q^{\prime}$ heterogeneity, was reduced under all experimental conditions. The retention component of the (a- A)D area was reduced significantly with L-NAME and L-NAME plus $\mathrm{CO}_{2}$, whereas the excretion component was reduced significantly under all experimental conditions. The decrease in logSD of ventilation distribution $\left(\log V^{\prime} \mathrm{SD}\right)$ was statistically significant after L-NAME and L-NAME plus $\mathrm{CO}_{2}$. There were no significant changes in the logSD of perfusion distribution $\left(\log Q^{\prime} \mathrm{SD}\right)$. Shunt fraction dropped significantly with $\mathrm{CO}_{2}$. There were no additive effects in any of these parameters with inspired $\mathrm{CO}_{2}$ following nebulized L-NAME. Inert gas dead space was unchanged throughout the study.
The mean number of lung pieces obtained from the animals was $797 \pm 270$. The SD of regional pulmonary blood flow decreased significantly with inhaled $\mathrm{CO}_{2}$, suggesting decreased heterogeneity of regional pulmonary blood flow (table 4). Further analysis of the microsphere data revealed a pattern consistent with fractal structure, as given by a fractal dimension of $\sim 1.14$. Regional blood flow in the lung is distributed in three-dimensional space, but, when characterized as a relative dispersion, the heterogeneity of the flow is decreased to a space with fractal dimension of 1.0-1.5 [27]. The greater the irregularity of the flow, the greater the fractal dimension. Neither inhaled $\mathrm{CO}_{2}$ nor L-NAME altered this dimension. Regression analysis of changes in regional pulmonary blood flow showed no significant alterations over time.

\section{Discussion}

The major findings of this study are that inspired $\mathrm{CO}_{2}$ and inhibition of pulmonary NOS (inhaled L-NAME) improve $V^{\prime} / Q^{\prime}$ heterogeneity but act in different fashions. Like L-NAME, inhaled $\mathrm{CO}_{2}$ caused a reduction in exhaled NO levels, but decreased $V^{\prime} / Q^{\prime}$ heterogeneity, at least in part, by decreasing the heterogeneity of regional pulmonary blood flow distribution. In contrast, L-NAME improved $V^{\prime} / Q^{\prime}$ heterogeneity but did not alter regional pulmonary blood flow. L-NAME did not add to the improvement in $V^{\prime} / Q^{\prime}$ matching already produced by inspired $\mathrm{CO}_{2}$. Inhaled $\mathrm{CO}_{2}$ reduces exhaled $\mathrm{NO}$ levels but its effect on pulmonary blood flow suggests that improved $V^{\prime} / Q^{\prime}$ matching with inspired $\mathrm{CO}_{2}$ is not mediated by a reduction in NO production. Lastly, these results suggest that endogenous NO production in the normal dog lung does not subserve $V^{\prime} / Q^{\prime}$ regulation.

Table 2. - Respiratory gas exchange measurements

\begin{tabular}{|c|c|c|c|c|}
\hline & Baseline & $\mathrm{CO}_{2}$ & L-NAME & $\mathrm{CO}_{2}+\mathrm{L}-\mathrm{NAME}$ \\
\hline $\mathrm{Pa}, \mathrm{O}_{2} \mathrm{mmHg}$ & $89 \pm 9$ & $101 \pm 9 *$ & $94 \pm 9$ & $103 \pm 9 *$ \\
\hline $\mathrm{Pa}_{\mathrm{a}} \mathrm{CO}_{2} \mathrm{mmHg}$ & $38 \pm 2$ & $56 \pm 4 * *$ & $37 \pm 4$ & $56 \pm 7 * *$ \\
\hline Arterial $\mathrm{pH}$ & $7.36 \pm 0.03$ & $7.25 \pm 0.03 * *$ & $7.35 \pm 0.04$ & $7.23 \pm 0.04 * *$ \\
\hline$P_{\mathrm{v}, \mathrm{O}_{2}} \mathrm{mmHg}$ & $43 \pm 3$ & $53 \pm 4 *$ & $44 \pm 4$ & $50 \pm 6$ \\
\hline$P \mathrm{E}, \mathrm{CO}_{2} \mathrm{mmHg}$ & $20 \pm 2$ & $48 \pm 2 * *$ & $21 \pm 2$ & $49 \pm 3 * *$ \\
\hline$P \mathrm{~A}, \mathrm{O}_{2} \mathrm{mmHg}$ & $106 \pm 7$ & $115 \pm 12 *$ & $109 \pm 7$ & $117 \pm 11 *$ \\
\hline$P A-a, \mathrm{O}_{2} \mathrm{mmHg}$ & $17 \pm 9$ & $13 \pm 9$ & $14 \pm 8$ & $14 \pm 6$ \\
\hline $\mathrm{Pa}-\mathrm{E}, \mathrm{CO}_{2} \mathrm{mmHg}$ & $18 \pm 2$ & $9 \pm 3 *$ & $15 \pm 3$ & $7 \pm 5^{*}$ \\
\hline
\end{tabular}

Data are presented as mean \pm SD. L-NAME: $N^{\omega}$-nitro-L-arginine methyl ester; $P_{\mathrm{a}}, \mathrm{O}_{2}:$ arterial oxygen tension; $P_{\mathrm{a}}, \mathrm{CO}_{2}$ : arterial carbon dioxide tension; $P_{\mathrm{v}}, \mathrm{O}_{2}$ : mixed venous oxygen tension; $P \mathrm{E}, \mathrm{CO}_{2}$ : mixed expiratory carbon dioxide tension; $P \mathrm{~A}, \mathrm{O}_{2}$ : alveolar oxygen tension; $P \mathrm{~A}-\mathrm{a}, \mathrm{O}_{2}$ : alveolar/arterial tension difference for oxygen; $P \mathrm{a}-\mathrm{E}, \mathrm{CO}_{2}$ : arterial $/$ mixed expiratory tension difference for carbon dioxide. ${ }^{*}: \mathrm{p}<0.05 ; * * \mathrm{p}<0.01$ versus baseline. $(1 \mathrm{mmHg}=0.133 \mathrm{kPa}$.) 
Table 3. - Inert gas exchange measurements

\begin{tabular}{|c|c|c|c|c|}
\hline & Baseline & $\mathrm{CO}_{2}$ & L-NAME & $\mathrm{CO}_{2}+$ L-NAME \\
\hline$(\mathrm{a}-\mathrm{A}) \mathrm{D}$ area & $0.637 \pm 0.225$ & $0.375 \pm 0.149 *$ & $0.312 \pm 0.145^{*}$ & $0.325 \pm 0.167 *$ \\
\hline$(\mathrm{a}-\mathrm{A}) \mathrm{DR}$ area & $0.19 \pm 0.09$ & $0.15 \pm 0.06$ & $0.13 \pm 0.07^{*}$ & $0.12 \pm 0.07^{*}$ \\
\hline (a-A)DE area & $0.29 \pm 0.13$ & $0.19 \pm 0.08^{*}$ & $0.15 \pm 0.07 *$ & $0.16 \pm 0.08 *$ \\
\hline $\log Q^{\prime} \mathrm{SD}$ & $0.871 \pm 0.185$ & $0.807 \pm 0.142$ & $0.807 \pm 0.156$ & $0.814 \pm 0.135$ \\
\hline $\log V^{\prime} \mathrm{SD}$ & $1.346 \pm 0.368$ & $1.15 \pm 0.442$ & $0.96 \pm 0.404^{*}$ & $0.929 \pm 0.363^{*}$ \\
\hline$Q^{\prime} \mathrm{sh} / Q^{\prime} \mathrm{t} \%$ & $0.8 \pm 1.0$ & $0.4 \pm 0.6^{*}$ & $0.4 \pm 0.4$ & $0.5 \pm 0.5$ \\
\hline$V_{\mathrm{D}} / V_{\mathrm{T}} \%$ & $42 \pm 9$ & $40 \pm 11$ & $44 \pm 11$ & $39 \pm 9$ \\
\hline
\end{tabular}

Data are presented as mean \pm SD. L-NAME: $N^{\omega}$-nitro-L-arginine methyl ester; (a-A)D: arterial/alveolar inert gas difference; (a-A)DR: retention component of (a-A)D; (a-A)DE: excretion component of (a-A)D; $Q^{\prime}$ SD: SD of perfusion distribution; $V^{\prime}$ SD: SD of ventilation distribution; $Q^{\prime} \mathrm{sh} / Q^{\prime} \mathrm{t}\left(Q^{\prime}\right.$ sh: shunt flow; $Q^{\prime} \mathrm{t}$ : total flow $)$ : inert gas shunt; $V_{\mathrm{D}} / V_{\mathrm{T}}$ : inert gas dead space; $V_{\mathrm{T}}$ : tidal volume. *: $\mathrm{p}<0.05$ versus baseline.

\section{Critique of methods}

Both inhaled NO and nebulized L-NAME [28] have been used to examine $V^{\prime} / Q^{\prime}$ relationships $[28,29]$ but this report represents the first use of inhaled NOS inhibitors in the evaluation of $V^{\prime} / Q^{\prime}$ heterogeneity in healthy animals. Despite widespread intravenous employment, the use of NOS inhibitors as inhaled agents has been limited. Aerosolized NOS inhibitors magnify the response to bronchoconstrictor and pulmonary vasoconstrictor challenges $[9,30]$ and reduce exhaled NO levels in asthmatic patients [31]. Although these studies demonstrate the activity of NOS inhibitors when delivered as aerosols certain questions remain unanswered. No study of inhaled NOS inhibitors describes what portion of the dose reaches the alveoli and the pulmonary vasculature, to what extent pulmonary NO production is altered and how much is absorbed systemically. To date, there have been no dose/ response studies with aerosolized NOS inhibitors.

In order to show that a selective and high degree of pulmonary NOS inhibition was achieved in the present study, pulmonary and systemic haemodynamic parameters were followed. Pulmonary pressures and PVR rose with inhaled L-NAME (table 1), consistent with other studies using high-dose intravenous NOS inhibitors but much less systemic vasoconstriction was observed [8, 24, 32]. This suggests a high but more selective blockade of lung NO production.

Since exhaled NO measurements were not available in these dogs, a further experiment was performed in five separate dogs in which exhaled NO levels were measured following inspired $\mathrm{CO}_{2}$, L-NAME and a combination of the two. Dogs have very low baseline levels of exhaled NO compared to several other species [19]. Nevertheless, a statistically significant decline in exhaled NO levels was demonstrated in these five dogs under all experimental conditions. Furthermore, haemodynamic changes (data

Table 4. - Microsphere pulmonary blood flow measurements

\begin{tabular}{ccccc}
\hline & Baseline & $\mathrm{CO}_{2}$ & L-NAME & $\begin{array}{c}\mathrm{CO}_{2}+ \\
\text { L-NAME }\end{array}$ \\
\hline $\mathrm{SD}^{+}$ & $0.376 \pm 0.051$ & $0.357 \pm 0.065 *$ & $0.407 \pm 0.08$ & $0.418 \pm 0.078$ \\
$\mathrm{D}^{+}$ & $1.138 \pm 0.054$ & $1.142 \pm 0.059$ & $1.14 \pm 0.055$ & $1.146 \pm 0.054$ \\
\hline
\end{tabular}

Data are presented as mean $\pm \mathrm{SD} .{ }^{+}$: of regional pulmonary blood flow. L-NAME: $N^{\omega}$-nitro-L-arginine methyl ester; D: fractal dimension. ${ }^{*}: \mathrm{p}<0.05$ versus baseline. not shown) in this separate set of experiments were similar in magnitude to those found in the original dogs. These data suggest that significant blockade of pulmonary NOS was produced in the initial set of experiments and similar reductions in exhaled NO levels were probably achieved.

Although greater and possibly complete NOS inhibition could have been achieved in the lung with higher doses, LNAME nebulization was discontinued when the mean systemic arterial pressure rose by $\sim 10 \%$ above baseline. The aim of delivering L-NAME via aerosol was to limit its impact on systemic vascular resistance and cardiac output since reduced cardiac output ( $<25 \%$ reduction) can itself lead to increased $V^{\prime} / Q^{\prime}$ heterogeneity [33]. In this way, essentially no change in cardiac output was observed (table 1).

The order of baseline conditions and NOS inhibition could not randomly be reversed due to the long duration of action of L-NAME, which inhibits NOS by $>90 \%$ [34] and causes sustained systemic hypertension for up to $2-4 \mathrm{~h}$ when given intravenously in dogs and rabbits [34, 35]. The sustained elevation of pulmonary artery and systemic blood pressure into the last measurement period suggests that there was a constant and near-maximal state of NOS inhibition following L-NAME nebulization throughout the last two experimental periods.

Although clinically healthy animals were studied, it is clear that baseline $V^{\prime} / Q^{\prime}$ distributions were abnormal in these dogs. Included in this group were several older dogs and this, in combination with mechanical ventilation, anaesthesia and the supine position, may have exaggerated their $V^{\prime} / Q^{\prime}$ abnormality. Despite the unexpected greater $V^{\prime} / Q^{\prime}$ heterogeneity (increased $\log Q^{\prime}$ SD and $\log V^{\prime}$ SD with normal shunt values), all the dogs tolerated the entire protocol without evident respiratory, haemodynamic or metabolic deterioration.

Differences between effects of $\mathrm{N}^{\omega}$-nitro-L-arginine methyl ester and carbon dioxide on gas exchange and haemodynamics

Despite similar improvements in $V^{\prime} / Q^{\prime}$ heterogeneity, as measured by the MIGET, L-NAME produced a smaller increase in arterial oxygenation than inspired $\mathrm{CO}_{2}$. Several factors may help to explain this difference. First, inspired $\mathrm{CO}_{2}$ caused a reduction in $V^{\prime} \mathrm{O}_{2}$, which led to a statistically significantly higher $P \mathrm{v}, \mathrm{O}_{2}$. In contrast, there was no change in $V^{\prime} \mathrm{O}_{2}$ with L-NAME, confirming similar previous observations in dogs [36]. Secondly, respiratory acidosis 
with inspired $\mathrm{CO}_{2}$ causes a rightward shift of the haemoglobin/oxygen dissociation curve (Bohr effect). Since both a higher $P_{\mathrm{v}, \mathrm{O}_{2}}$ and a rightward shift of the haemoglobin/oxygen dissociation curve reduce $P \mathrm{~A}-\mathrm{a}, \mathrm{O}_{2}$ for any given $P \mathrm{~A}, \mathrm{O}_{2}$ and venous admixture [37], inspired $\mathrm{CO}_{2}$ would be expected to generate a higher $\mathrm{Pa}_{\mathrm{a}} \mathrm{O}_{2}$ than $\mathrm{L}-$ NAME despite equal $V^{\prime} / Q^{\prime}$ heterogeneity reduction. Both $\mathrm{CO}_{2}$ and L-NAME elicited modest increases in pulmonary artery pressure but PVR was increased only with L-NAME.

Effects of inspired carbon dioxide and nitric oxide synthesis inhibition on ventilation/perfusion ratio heterogeneity

Both inspired $\mathrm{CO}_{2}$ and inhaled L-NAME improved $V^{\prime} /$ $Q^{\prime}$ matching. The improvement in $V^{\prime} / Q^{\prime}$ with inhaled LNAME is a novel finding and accords with the results of VENEGAS et al. [38], who found that inhaled NO (40 parts per million (ppm)) increased the spatial heterogeneity of $V^{\prime} / Q^{\prime}$ in supine dogs measured by positron emission tomography, although Hopkins et al. [39] found no $V^{\prime} / Q^{\prime}$ deterioration in anaesthetized dogs given $80 \mathrm{ppm}$ NO. Deterioration in $V^{\prime} / Q^{\prime}$ matching with inhaled NO has also been shown in studies of patients with chronic obstructive pulmonary disease [40] and in normal humans $[40,41]$. Two recent studies found a trend towards better gas exchange with partial elimination or diversion of endogenous NO production. SetTERGRen et al. [42] eliminated the autoinhalation of nasal and sinus NO in humans and FAGAN et al. [43] abolished endothelial cell production of NO in a knockout mouse deficient in endothelial NOS. These findings strongly suggest the intriguing possibility that endogenous basal NO production in the lung or upper respiratory tract does not serve the purpose of regulating $V^{\prime} / Q^{\prime}$. The basis for worsened gas exchange and increased $V^{\prime} / Q^{\prime}$ heterogeneity with inhaled $\mathrm{NO}$ and their improvement with NOS inhibition in lungs without significant shunt may, in part, represent release of hypoxic pulmonary vasconstriction (HPV) by NO [8] and enhanced HPV with NOS inhibition [29, 44]. Supporting the concept that increased HPV may improve gas exchange, it has been shown that ventilation with slightly hypoxic air $\left(F \mathrm{I}, \mathrm{O}_{2}, 0.15\right)$ in dogs reduces $V^{\prime} / Q^{\prime}$ heterogeneity [3]. However, this may not be the entire explanation as predominantly greater improvement with NOS inhibition of the retention component of the (a-A)D area, which should reflect a reduction in the number of lung units with low $V^{\prime} / Q^{\prime}$ as HPV is enhanced, was not found.

The ability of inspired $\mathrm{CO}_{2}$ to reduce $V^{\prime} / Q^{\prime}$ heterogeneity probably stems from some combination of its multiple effects on airways, nerves, parenchyma and vessels $[4,5] . \mathrm{CO}_{2}$ dilates small airways and improves collateral ventilation but can evoke vagally mediated large airway bronchoconstriction [45-48]. INGRAM [2] found that parenchymal compliance was increased with inspired $\mathrm{CO}_{2}$, possibly as a result of enhanced surfactant function at a more acid $\mathrm{pH}$ [49]. The vascular effects of $\mathrm{CO}_{2}$ are not as easily described since low $\mathrm{pH}$ causes vasoconstriction and enhances HPV [50], but, in some experimental situations, there may be a direct opposing vasodilator effect of molecular $\mathrm{CO}_{2}[51,52]$.
Although it was the authors' original hypothesis that inspired $\mathrm{CO}_{2}$ might reduce $V^{\prime} / Q^{\prime}$ heterogeneity by suppressing lung NO production, the data did not support this concept.

First, $\mathrm{CO}_{2}$ reduced regional perfusion heterogeneity but this did not occur when even greater suppression of $\mathrm{NO}$ production was achieved with L-NAME. Secondly, although exhaled $\mathrm{NO}$ levels fell with inspired $\mathrm{CO}_{2}$, this may be partially due to the increased cardiac output and thus greater $\mathrm{NO}$ scavenging by haemoglobin [35]. Finally, $\mathrm{CO}_{2}$ has significantly greater effects on airway tone than vascular tone [5], whereas the opposite is true for NO [53, 54].

Both $\mathrm{CO}_{2}$ and L-NAME may improve $V^{\prime} / Q^{\prime}$ matching through changes in regional ventilation distribution which were not directly measured. There were no changes in airway pressures during fixed ventilation with L-NAME or $\mathrm{CO}_{2}$, but more sophisticated measurement of airway resistance and direct measurement of regional ventilation (such as with simultaneous inhaled and injected microspheres) would be necessary to assign changes in bronchomotor tone and ventilation as contributors to the $\mathrm{CO}_{2}$ or the L-NAME effect.

The finding of improved $V^{\prime} / Q^{\prime}$ matching and decreased $V^{\prime} \mathrm{O}_{2}$ and $V^{\prime} \mathrm{CO}_{2}$ in these $\operatorname{dogs}$ may represent further justification for the clinical application of permissive hypercapnia [55]. In fact, these results may suggest a rationale for the careful addition of exogenous $\mathrm{CO}_{2}$ to inspired gas. However, it must be stated that these experiments were not performed under conditions of lung injury or multiple system organ dysfunction. Furthermore, although inhaled L-NAME also improved $V^{\prime} / Q^{\prime}$ matching, the ubiquity and many functions of the NO system require further study before using inhaled L-NAME to help in the face of severe hypoxaemic respiratory failure.

In conclusion, it was found that inhibition of lung nitric oxide synthase and loss of endogenous nitric oxide production reduces ventilation/perfusion ratio heterogeneity. This intriguing finding suggests that endogenous nitric oxide production plays no important role in ventilation/ perfusion ratio regulation; however, further study is necessary. Although inspired carbon dioxide caused a reduction in exhaled nitric oxide levels, it is unlikely that this entirely explains how inspired carbon dioxide improves gas exchange. Inspired carbon dioxide narrowed the heterogeneity of pulmonary blood flow, which was not seen with nitric oxide synthase inhibition. Whether inspired carbon dioxide and nitric oxide synthase inhibitors act similarly in other ways to reduce ventilation/perfusion ratio heterogeneity or by separate mechanisms will require more investigation from the cellular level to the whole animal.

Acknowledgements. The authors wish to thank M. Middaugh, T. Tran and M. Kerr for their excellent technical contributions in these studies.

\section{References}

1. Haas F, Bergofsky EH. Effect of pulmonary vasoconstriction on balance between alveolar ventilation and perfusion. J Appl Physiol 1968; 24: 491-497. 
2. Ingram RH. Effects of airway versus arterial $\mathrm{CO}_{2}$ changes on lung mechanics in dogs. J Appl Physiol 1975; 38: 603607.

3. Swenson ER, Robertson HT, Hlastala MP. Effects of inspired carbon dioxide on ventilation-perfusion matching in normoxia, hypoxia, and hyperoxia. Am J Respir Crit Care Med 1994; 149: 1563-1569.

4. Nattie EE. Gas exchange in acid-base disturbances. In: Fishman AP, ed. The Respiratory System. Volume IV. Gas Exchange. Baltimore, MD, Waverly Press, 1986; pp. 421-438.

5. Swenson ER, Domino KB, Hlastala MP. Physiologic effects of oxygen and carbon dioxide. In: Hlastala MP, Robertson HT, eds. Complexities in Structure and Function of the Lung. New York, NY, Marcel Dekker Inc, 1998; pp. 511-547.

6. Farrukh IS, Gurtner GH, Terry PB, et al. Effect of $\mathrm{pH}$ on pulmonary vascular tone, reactivity, and arachidonate metabolism. J Appl Physiol 1989; 67: 445-452.

7. Twort CHC, Cameron IR. Effects of $\mathrm{PCO}_{2}, \mathrm{pH}$, and extracellular calcium on contraction of airway smooth muscle from cats. Respir Physiol 1968; 66: 259-267.

8. Leeman M, De Beryl VZ, Delcroix M, Naeije R. Effects of endogenous nitric oxide on pulmonary vascular tone in intact dogs. Am J Physiol 1994; 266: H2343-H2347.

9. Putensen C, Rasanen J, Lopez FA. Improvement in $V^{\prime} \mathrm{A} /$ $Q^{\prime}$ distributions during inhalation of nitric oxide in pigs with methacholine-induced bronchoconstriction. Am J Respir Crit Care Med 1995; 151: 116-122.

10. Li CG, Rand MJ. Evidence that part of the NANC relaxant response of the guinea pig trachea to electrical field stimulation is mediated by nitric oxide. $\mathrm{Br} J$ Pharmacol 1991; 102: 91-94.

11. Iadecola C. Does nitric oxide mediate the increases in cerebral blood flow elicited by hypercapnia. Proc Natl Acad Sci U S A 1992; 89: 3913-3916.

12. Fleming I, Hecker M, Busse R. Intracellular alkalinization induced by bradykinin sustains activation of the constitutive nitric oxide synthase in endothelial cells. Circ Res 1994; 74: 1220-1226.

13. Horvath I, Sandor NT, Ruttner Z, McLaughlin AC. Role of nitric oxide in regulating cerebrocortical oxygen consumption and blood flow during hypercapnia. J Cereb Blood Flow Metab 1994; 14: 503-509.

14. Gurevicius J, Salem MR, Metwally AA, Silver JM, Crystal GJ. Contribution of nitric oxide to coronary vasodilation during hypercapnic acidosis. Am J Physiol 1995; 268: H39-H47.

15. Yaqoob M, Edelstein CL, Wieder ED, et al. Nitric oxide kinetics during hypoxia in proximal tubules: effects of acidosis and glycine. Kidney Int 1996; 49: 1314-1319.

16. Gorren ACF, Schrammel A, Schmidt K, Mayer B. Effects of $\mathrm{pH}$ on the structure and function of neuronal nitric oxide synthase. Biochem $J$ 1998; 331: 801-807.

17. Bannenberg GL, Giammarresi C, Gustafsson LE. Inhaled carbon dioxide inhibits lower airway nitric oxide formation in the guinea pig. Acta Physiol Scand 1997; 160: 401-405.

18. Stromberg S, Lonnquist PA, Persson MG, Gustafsson LE. Lung distension and carbon dioxide affect pulmonary nitric oxide formation in the anaesthetized rabbit. Acta Physiol Scand 1997; 159: 59-67.

19. Carlin RE, Ferrario L, Boyd JT, Camporesi EM, McGraw DJ, Haim TS. Determinants of nitric oxide in exhaled gas in the isolated rabbit lung. Am J Respir Crit Care Med 1997; 155: 922-927.

20. Yamaguchi K, Takasugi T, Fujita H, et al. Endothelial modulation of $\mathrm{pH}$-dependent pressor response in isolated perfused rabbit lungs. Am J Physiol 1996; 270: H252$\mathrm{H} 258$.

21. Wagner PD, Saltzman HA, West JB. Measurement of continuous distributions of ventilation-perfusion ratios: theory. J Appl Physiol 1974; 36: 588-599.

22. Wagner PD, Naumann PF, Lavaruso RB. Simultaneous measurement of eight foreign gases in blood by gas chromatography. J Appl Physiol 1974; 36: 600-605.

23. Hlastala MP, Robertson HT. Inert gas elimination characteristics of the normal and abnormal lung. J Appl Physiol 1978; 44: 258-266.

24. Perella MA, Edell ES, Krowka MJ, Cortese DA, Burnett JC. Endothelium-derived relaxing factor in pulmonary and renal circulations during hypoxia. Am J Physiol 1992; 263: R45-R50.

25. Rodriguez-Roisin R, Wagner PD. Interplay of intrapulmonary and extrapulmonary factors on pulmonary gas exchange during weaning. Intensive Care Med 1991; 17: 249-251.

26. Glenny RW, Bernard S, Brinkley M. Validation of fluorescent-labeled microspheres for measurement of regional organ perfusion. J Appl Physiol 1993; 74: 2585-2597.

27. Glenny RW, Robertson HT. Fractal properties of pulmonary blood flow: characterization of spatial heterogeneity. $J$ Appl Physiol 1990; 69: 532-545.

28. Gomez FP, Barbera JA, Roca J, et al. Effect of nitric oxide synthesis inhibition with L-NAME on ventilation-perfusion distributions in bronchialasthma. Eur Respir J 1998; 12: 865-871.

29. Putensen C, Rasanen J, Downs JB. Effect of endogenous and inhaled nitric oxide on the ventilation-perfusion relationships in oleic-acid lung injury. Am J Respir Crit Care Med 1994; 150: 330-336.

30. Freden F, Berglund JE, Reber A, Hogman M, Hedenstierna G. Inhalation of a nitric oxide synthase inhibitor to a hypoxic or collapsed lung lobe in anaesthetized pigs: effects of pulmonary blood flow distribution. $\mathrm{Br} J \mathrm{An}$ aesth 1996; 77: 413-418.

31. Kharitonov SA, Yates D, Robbins RA, Logan-Sinclair R, Shinbourne EA, Barnes PJ. Increased nitric oxide in exhaled air of asthmatic patients. Lancet 1994; 343: 133-135.

32. van Gelderen EM, Boer MOD, Saxena PR. $N^{\omega}$-nitro-Larginine methyl ester: systemic and pulmonary haemodynamics, tissue blood flow, and arteriovenous shunting in the pig. Naunyn Schmiedebergs Arch Pharmacol 1993; 348: 417-423.

33. Ohlsson J, Middaugh M, Hlastala MP. Reduction of lung perfusion increases $V^{\prime} \mathrm{A} / Q^{\prime}$ heterogeneity. J Appl Physiol 1989; 66: 2423-2430.

34. Traystman RJ, Moore LE, Halfaer MA, et al. Nitro-Larginine analogues: dose- and time-related nitric oxide synthase inhibition in brain. Stroke 1995; 26: 864-869.

35. Persson MG, Longvist PA, Gustafsson LE. Positive endexpiratory pressure ventilation elicits increases in endogenously formed nitric oxide as detected in air exhaled by rabbits. Anesthesiology 1995; 82: 969-974.

36. Shen W, Xiaobin X, Ochoa M, Zhao G, Wolin MS, Hintze $\mathrm{TH}$. Role of nitric oxide in the regulation of oxygen consumption in conscious dogs. Circ Res 1994; 75: 10861095.

37. Turek Z, Kreuzer F. Effects of shifts of the $\mathrm{O}_{2}$ dissociation curve upon alveolar-arterial $\mathrm{O}_{2}$ gradients in computer models of the lung with ventilation perfusion mismatching. Respir Physiol 1981; 45: 133-139.

38. Venegas J, Trepo S, Mialovoic S, Zapol W, Hales G. Effects of inhaled $\mathrm{NO}$ in the spatial heterogeneity of 
pulmonary perfusion $\left(Q^{\prime}\right)$, ventilation $\left(V^{\prime} \mathrm{A} ;\right)$ and $V^{\prime} \mathrm{A} / Q^{\prime}$. FASEB J 1994; 6: A691.

39. Hopkins SR, Johnson EC, Richardson RS, Wagner H, de Rosa M, Wagner PD. Effects of inhaled nitric oxide on gas exchange in lungs with shunt or poorly ventilated areas. Am J Respir Crit Care Med 1997; 156: 484-491.

40. Katayama Y, Higenbottam TW, Diaz de Atauri MJ, et al. Inhaled nitric oxide and arterial oxygen tension in patients with chronic obstructive pulmonary disease and severe pulmonary hypertension. Thorax 1997; 52: 120-124.

41. Durand F, Mucci P, Safont L, Prefaut C. Effects of nitric oxide inhalation on pulmonary gas exchange during exercise in highly trained athletes. Acta Physiol Scand 1999; 165: 169-176.

42. Settergren G, Angdin M, Astudillo R, et al. Decreased pulmonary vascular resistance during nasal breathing: modulation by endogenous nitric oxide from the paranasal sinuses. Acta Physiol Scand 1998; 163: 235-239.

43. Fagan KA, Fouty BW, Tyler RC, et al. The pulmonary circulation of homozygous or heterozygous eNOS-null mice is hyperresponsive to mild hypoxia. J Clin Invest 1999; 103: 291-299.

44. Shirai M, Shimouchi A, Kawaguchi AT, Ikeda S, Sungawa K, Ninomiya I. Endogenous nitric oxide attenuates hypoxic vasoconstriction of small pulmonary arteries and veins in anesthetized cats. Acta Physiol Scand 1997; 159: 263-264.

45. Delpierre S, Jammes Y, Mei M, Mathiot MJ. Mise en evidence de l'origine vagale reflexe des effete bronchoconstricteurs du in vivo chez le chat. $J$ Physiol (Paris) 1980; 76: 889-891.

46. Severinghaus JW, Swenson EW, Finley TN, Lategola MT,
Williams J. Unilateral hypoventilation produced in dogs by occluding one pulmonary artery. J Appl Physiol 1961; 16: $53-60$.

47. Sterling GM. The mechanism of bronchoconstriction due to hypocapnia in man. Clin Sci 1968; 34: 277-285.

48. Traystman RJ, Terry PB, Menkes HA. Carbon dioxide: a major detenninant of collateral ventilation. $J$ Appl Physiol 1984; 45: 69-74.

49. Wildeboer-Venema F. Influences of nitrogen, air and alveolar gas upon surface tension of lung surfactant. Respir Physiol 1984; 58: 1-14.

50. Dawson CA. Role of pulmonary vasomotion in physiology of the lung. Physiol Rev 1984; 64: 544-616.

51. Brimioulle S, Lejeune P, Vachiery J-L, Leeman M, Melot C, Naeije R. Effects of acidosis and alkalosis on hypoxic pulmonary vasoconstriction in dogs. Am J Physiol 1990; 258: H347-H353.

52. Grover RB, Wagner WW, McMurtry IF, Reeves JT. Pulmonary circulation. In: Shepherd JT, Abboud FM, eds. The Cardiovascular System. Volume 3. Peripheral Circulation and Organ Blood Flow. Baltimore, MD, Waverly Press, 1983; pp. 103-136.

53. Sasaki F, Pare PD, Ernest D, et al. Endogenous nitric oxide influences acetylcholine induced bronchovascular dilation in sheep. J Appl Physiol 1995; 78: 539-545.

54. Maniscalco M, Sofia M, Smith A, et al. Lack of effect of nitric oxide inhibition on bronchial tone and methacholine-induced bronchoconstriction in man. Respir Med 1997; 91: 335-340.

55. Laffey JG, Kavanagh BP. Carbon dioxide and the critically ill - too little of a good thing. Lancet 1999; 354 : 1283-1286. 